\title{
WHAT HAVE WE LEARNED?
}

\section{Social crime prevention in SA: A critical overview ${ }^{1}$}

Cheryl Frank, O pen Society Foundation

Cheryl@ct.osf.org.za

Crime prevention is a relatively new enterprise in South Africa, and the nature of progress in this area has been mixed. While much activity has been noted, particularly among civil society organisations, the generation and utilisation of information is an area of weakness. Key questions remain: how to promote government accountability for service delivery, and how crime prevention advocates engage with issues such as human rights and the strengthening of democracy.

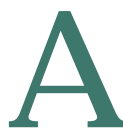
s with any emerging enterprise, it is always useful to review developments over time and to offer critical assessments of progress. With crime prevention and reduction in South Africa, this is even more important, given the many definitional, political and contextual variables that complicate this field. This article seeks to offer a brief review of developments in policy and practice over the past three years, with some reference to other reviews of this nature. This article will not engage in any definitional discussions relating to crime prevention vs. reduction but will broadly discuss initiatives intended to both prevent or reduce crime, and will be biased towards developments relating to social crime prevention. Only a superficial overview is possible in the context of this article, and references to other documents providing further detail are offered in the text.

\section{Thinking again about crime prevention}

The crime prevention discourse over the past three years has remained in a distinctly technical terrain, engaging in the details of projects and programmes, and to a great degree disregarding some of the broader questions that ought to be addressed. South
Africa is characterised by deep economic and social division, a rapidly changing environment, and a population that is under severe pressure from poverty, crime and HIV/Aids, among other factors. It is critical to consider how inequality, poverty, and strategies for development feature in the crime prevention discourse. $^{2}$

Crime prevention is as political a venture as any other project to effect social change. It requires engagement with questions relating not only to the perpetual prevention vs. law enforcement concern; but more broadly with regard to how social justice, human rights, and democracy feature in this endeavour. It could be argued that many kinds of crime may be very functional responses to challenging social, economic and cultural conditions. Foremost in this discourse, therefore, should be the continued examination of crime prevention choices and of whose interests are being served by these choices. Allied to this is the question of how a critical civil society should act in this environment.

O verall, our notions of crime prevention have remained state-centred and this has created both 
intellectual and practical limitations. Social crime prevention needs to be recognised as strongly in the domain of civil society, with the state playing any number of roles to support, facilitate or enable such activity. It is, however, by no means fundamental to this endeavour.

\section{G overnment and crime prevention}

Policy developments

The policy environment that relates directly to crime prevention has remained relatively static over the past few years (this has been discussed in detail by others ${ }^{3}$ ); however, there have been some developments that warrant discussion. With regard to national government, it would seem that the impetus for crime prevention created by the $\mathrm{N}$ ational Crime Prevention Strategy has all but been lost, given the emphasis on law enforcement strategies. Some of the principles of the NCPS have, however, emerged in the Urban Renewal Programme. ${ }^{4}$

A brief resurgence of social crime prevention was noted in 2002 when the social cluster within national government engaged in a process to identify each department's programmes in this area. Civil society organisations were not engaged in this process. It is unclear as to what has become of this, except that it is now the responsibility of the Department of Arts and Culture. This department is also responsible for another recent government project, the Moral Regeneration Movement. While the premises of this 'movement' may echo ideas about values expressed in the NCPS, its language and appeals to a common morality have been met with scepticism. This notwithstanding, the process will be important to watch.

W hile the ability of the criminal justice system to promote crime prevention is often questionable, proposed new legislation may offer some opportunities for crime prevention. When enacted, new Child Justice legislation will create opportunities for crime prevention through diversion and alternative sentencing. Although diversion has been practiced for some time, the difference will be that government will be expected to create broad access to these services, and to pay for their provision. The Children's Bill also has great potential for this kind of impact but requires much campaigning in order to maximise these possibilities in the provisions of the Bill. It is certain that there are other pieces of legislation that will offer such value and it requires that crime prevention advocates maintain some vigilance in this area. It is also worth noting that the 1998 W hite Paper on Safety and Security is due to complete its five-year term. This, and the expected review of the SAPS Act could also offer some opportunity for furthering the crime prevention agenda, notwithstanding the limitations of the police in this area.

Probably some of the more interesting developments are occurring at the level of local government, offering credence to some of the early optimism for the role of local government in crime prevention. ${ }^{5}$ Some of the impetus for this has come from the U rban Renewal Programme, which is a multidisciplinary attempt to engage safety and security concerns into a programme for urban development. This has been comprehensively review ed elsewhere. ${ }^{6}$ Integrated Development Plans are also being seen as critical opportunities to include crime prevention and security concerns into local development planning. This is an emerging area and should also be watched.

Several recent initiatives have also aimed to assist local government to develop and implement crime prevention strategies. There is every indication that this can be done quite successfully, but that very specific conditions apply to good practice.

'Joined-up government,' or delivery on core function?

A key question continues to be whether the energy of government departments should be directed at intersectoral governance, or should be focused on the fulfilment of their core functions. While it is difficult to argue these as mutually exclusive, it is worth considering where the focus and concentration of government should be. In N ovember 2002 Pelser and Louw ${ }^{8}$ argued for an initial focus on the latter (especially by departments considered to be central to crime prevention), given the pressure for service delivery and the inability of government departments to respond to this. Now, a year later, this argument still carries considerable weight, given the continued trend of limited delivery. 
Their argument is given further substance when examining the key functions of some of these departments and the fact that many would have a certain crime prevention impact if they succeeded in delivery on their core functions. Creating access to schooling for all, and the extension and improvement of the quality of early childhood development services, relating to the Departments of Education and Social D evelopment, are just two examples. This then raises the central question of how these departments are to held accountable for this delivery.

\section{Civil society and crime prevention}

There is no question that civil society organisations have been the most energetic and committed proponents of social crime prevention. A disparate range of organisations, including $\mathrm{NGOS}, \mathrm{CBO} s$ and faith-based organisations undertake activities based on a range of interests. These include security, human rights, development, public health, and a range of sectoral interests such as children, young people, women, and the elderly. O ver the past three to five years a great deal of learning has been generated by these organisations in a range of areas, sometimes in partnership with government, and this is discussed in more detail later. While great strides have undoubtedly been made, overall much of this work has suffered from a lack of rigour, which is also discussed later.

A further concern relates to how new 'knowledge' and learning is disseminated and used. While significant information is being generated by the larger organisations, the great difficulty lies in how this new information can be made to serve local needs. This essentially involves creating an exchange with smaller, more community-based organisations, whose own experiences will also strengthen this knowledge base. There are currently few mechanisms to do this, but the range of membership networks and forums may offer some opportunities in this regard. O ne issue is, however, becoming palpably clear: the practice of disseminating research and documentation is not enough to transfer new information, and to enable the translation of new learning into practice.

A final point relates to civil society's role of oversight and promoting government accountability. The experience in crime prevention thus far has been a drive towards partnerships with government. This undoubtedly compromises the oversight role, however hard civil society organisations may attempt to finesse and balance these conflicting roles. The obligation of accountability to the public by civil society organisations is also of issue. The practice of making claims of success in the absence of strong evidence is as problematic as is unaccountable government. Especially when NGO s are powerful, with international profile, and programme beneficiaries are poor communities with limited resources, greater obligations towards transparency and accountability are created.

\section{The role of the general public}

The criminal justice system relegates citizens to two neat categories: offender and victim, and affords only a very limited additional role to citizens, for instance participation in community policing forums. Interesting questions for crime prevention practitioners are what role should be assigned to the ordinary citizen, and how citizens would define their own roles. In recent experience, the role most often promoted is that of volunteer, and NGO s have sought to engage citizens into service as life-skills trainers, counsellors, youth mentors, victim support providers, etc. Given that many crime prevention initiatives are directed at poor communities, the people engaged in these activities are often poor, unemployed women. In a context of great inequality, it is necessary to question what demands are made on those already under significant pressure. Are appropriate 'contracts' negotiated? Do these exchanges benefit the volunteer in a real and enduring way? A further question is how middle class suburbanites may be engaged. This group has been the beneficiary of a great many advantages, is in possession of many useful skills, and often has the personal resources to assist; yet such people are recruited on a very limited basis.

\section{G enerating learning in crime prevention: practice, documentation and evaluation}

O ne of the central questions that we seek to answer is: W hat have we learned about crime prevention? This begs the question: What constitutes learning? O ne of the greatest weaknesses in the work generated thus far has been a general lack of scientific rigour. This has various dimensions but begins with a weak engagement with programme 
theory. Very few crime prevention initiatives are able to articulate the set of theoretical and process assumptions that motivate and rationalise the interventions that are undertaken in the field, and these initiatives are seldom informed by local and international research findings. This weakness permeates the programme planning process, and these factors conspire to frustrate any process of evaluation.

Evaluation is also an area of concern. There is limited commitment to well-documented and appropriately evaluated crime prevention initiatives, and this presents great problems for the construction of learning that can be used by others. This w eakness is evident in the strategies even of some of the larger, more resourced NGOs. While it is acknowledged that evaluations that have a high degree of methodological rigour can be expensive, it is true that there is a range of information available about how best evaluation may be addressed, which need not be expensive if integrated into programme planning and implementation. It is also necessary to continue to learn about evaluation, in order that informed decisions may be made. The philosophy offered by a 'utility-focused' ${ }^{9}$ approach, and 'realistic evaluation' ${ }^{10}$ both offer useful, but different pathways into evaluation strategy.

There is no doubt that our ability to work with information is a critical factor in driving crime prevention in South Africa, and that weaknesses in both the generation and the utilisation of information need to be addressed.

W hat have we learned thus far, and what are the gaps?

Children and youth: preventing offending and victimisation

Children and young people have been obvious targets for crime prevention interventions, in terms of the prevention of both offending and victimisation. Much learning has been generated by those organisations working with youth at risk, especially in the context of diversion and offender reintegration services. For instance, a review of 16 different programmes for youth is currently being undertaken by the $O$ pen Society Foundation and will be available in February 2004. This review includes the work of organisations such as Nicro, Educo, Khulisa, and the National Peace Accord Trust. Some longitudinal evaluation data is also available. ${ }^{11}$ However, there is a still little information available about how generic programmes such as sports and recreation, life skills, and employment creation contribute to crime prevention.

Schools present an interesting challenge. While some valuable learning has been generated in relation to school safety, ${ }^{12}$ it is also true that the piecemeal interventions that can be offered by NG O s cannot be the basis for promoting safety in the over 27,000 schools in the country. Mechanisms to promote school safety clearly have to be integrated into how schools and school districts are run. This requires that a minimum set of expectations in this regard is established for these schools and districts. This kind of thinking has, however, yet to surface within government.

The range of victimisation of children and young people (e.g. child abuse, child labour, sexual exploitation, gun violence) is complex and disparate and has yet to be addressed in any meaningful way. It is also true that the victimisation debate is skewed in relation to child victimisation, and the range of ways in which young people, especially young men, are victimised, has received far less attention. Some new work with great potential is emerging in relation to the prevention of child victimisation, e.g. home visiting programmes (such as offered by the Parent Centre in Cape Town) and after-school care programmes, ${ }^{13}$ but it is still too early to discuss their impact.

\section{Preventing violence against women}

The country's overall engagement with the issue of violence against women has been appalling, and from the perspective of prevention, the issue continues to confound us. The perceived intractability of the problem has created a difficult intellectual impasse and there is no doubt that an injection of new energy is needed to shift this debate forward.

While specialists in this field have been engaged in service provision and lobbying in relation to the 
needs of the high numbers of victims, attention to the question of prevention has been limited. Innovative ideas relating to prevention are scarce, ${ }^{14}$ but some are currently being tested. These include:

- Gender-based violence education in schools (for instance the programme offered by the School for Public Health at the U niversity of the Western Cape);

- Community-based safety promotion (A project to test women-led safety promotion is being implemented by the UNISA Centre for Social and Health Sciences);

- Working with men to enrich family life (Embizweni, a programme based in Khayelitsha in the Western Cape, undertakes one such programme).

This sector is hugely conflicted on the question of programmes for perpetrators, for example in the area of domestic violence. This has resulted in few tests in this area, and limited information about the value of such approaches. Another gap in information relates to the role of victim support services in crime prevention, and further information in this regard would be useful. O verall, it is true that the experts in this sector have yet to apply themselves to the issue of prevention in a focused way, and this is critical to pushing this discussion forward.

Local crime prevention

Crime prevention initiatives focused on geographical areas have proved to be the most labour and resource intensive, but a fair degree of learning has emerged. Much of this relates to partnerships and co-ordination, structures for crime prevention, and the question of scale of these initiatives. ${ }^{15} \mathrm{O}$ nly very limited work of this nature has been undertaken in rural or peri-urban areas. ${ }^{16}$ Some very useful learning is available on how crime prevention strategies and programmes may be embedded into the operations of local government. ${ }^{17}$

There is no question that this is a difficult area of work, and generating knowledge here is inextricably tied to development issues in local communities. It is here that questions relating to the point where crime and development meet, are most tangible, offering valuable opportunities for learning in this regard.
Violence

The issue of violence remains a critical problem, yet new ideas relating to prevention have largely been elusive. The public health sector (particularly the MRC and the Centre for Social and Health Sciences at UNISA) is offering valuable baseline data; and is also setting high standards in terms of methodological rigour. The $\mathrm{N}$ ational Injury and Mortality Surveillance System, and the Crime, Violence and Injury Lead Programme are examples of such data. Thus far, how ever, it is still too early to demonstrate impact in relation to prevention. It cannot but be noted however, that much of the problem is conceptual, and work in this area needs to remain a constant focus.

\section{Issues for the future}

Generating learning

The crime prevention enterprise is unequivocally dependent on the quality of information that is produced, and here an argument is being made for a much more information-driven approach to crime prevention. Such an approach requires far greater attention to programme theory, evaluation and documentation, and is centrally about the development of technical skills relating to the management and utilisation of information. This kind of approach will enable a far more critical approach to issues such as the ability to replicate models and programmes (thus far proved to be a myth), and requires equal commitment from donors and NGOs.

Building technical skills for crime prevention, and providing support where this is needed, is also critical to the future of this enterprise. A national crime prevention centre, as discussed by Pelser and Louw, ${ }^{18}$ could be a valuable driver of the emerging crime prevention enterprise in South Africa. Such a structure would however have to be appropriately skilled and resourced, and maintain a critical distance from government.

Human rights, democracy, accountability and development

These issues remain absent from crime prevention debates, notwithstanding clear indications of the erosion of some key human rights principles in response to the high levels of crime. ${ }^{19}$ As crime 
prevention advocates seek to build technical skills and knowledge, we cannot afford to be naïve about the broader social, economic and political forces that actively shape the risk factors for crime. This more global view is essential to understanding both current realities and foreseeing future adversity.

\section{Endnotes}

1 Some of the ideas in this article were presented at a USAID Experts Meeting on Crime Prevention held in November 2002.

2 This issue was addressed in a recent workshop hosted by the $O$ pen Society Foundation. The report can be accessed at www.osf.org.za.

3 J Rauch. 2002. Changing Step: crime prevention policy in South Africa. In Pelser (ed), Crime Prevention Partnerships: Lessons from Practice. Pretoria: Institute for Security Studies.

4 J Rauch. 2003. Thinking Big: The National U rban Renewal Programme and Crime Prevention in South Africa's M etropolitan Cities. Johannesburg: Centre for the Study of Violence and Reconciliation.

5 M Shaw. The Role of Local Government in Crime Prevention in South Africa. ISS Paper 33. August 1998

6 J Rauch. 2003, op. cit. Thinking Big: The National U rban Renewal Programme and Crime Prevention in South Africa's M etropolitan Cities. Johannesburg: Centre for the Study of Violence and Reconciliation.

7 R G riggs. Forthcoming. Lessons from Local Crime Prevention. Cape Town: O pen Society Foundation for South Africa.

8 E Pelser and A Louw. A Critical Assessment of Crime Prevention. S A Crime Q uarterly N o.2. November 2002.

9 M Quinn-Patton. 1996. Utilization-Focused Evaluation. N ew York: Sage Publishers.

10 R Pawson and N Tilley. 1998. Realistic Evaluation. London: Sage Publishers.

11 L M untingh. 2001. The Effectiveness of Diversion Programmes - a longitudinal evaluation of cases. Cape Town: NICRO.

12 R Griggs. 2002. Preventing Crime in Schools in South Africa: a review of learning and good practice. Cape Town: O pen Society Foundation for South Africa. (http://www.osf.org.za).

13 Partners with After-School Care Projects (PASCAP) is testing after-school care programmes in the Western Cape and the Eastern Cape. (http://www.pascap.org.za).

14 In 2001 and 2002, the Criminal Justice Initiative at the O pen Society Foundation hosted workshops intended to generate discussion and debate about the prevention of violence against women. These reports are available at www.osf.org.za.

15 R Griggs. Forthcoming. Lessons from Local Crime Prevention. Cape Town: O pen Society Foundation for
South Africa. Pelser (2002) also provides valuable insights in relation to this in Crime Prevention Partnerships: Lessons from Practice. Pretoria: Institute for Security Studies.

16 P M athabathe and T Shabangu. 2001. Bolobedu: Towards an intervention strategy to prevent crime and violence in rural South Africa. Pretoria: IDASA.

17 R Griggs. forthcoming. Lessons from Local Crime Prevention. Cape Town: O pen Society Foundation for South Africa.

18 E Pelser and A Louw. A Critical Assessment of Crime Prevention. S A Crime Q uarterly N o.2. N ovember 2002.

19 These are analysed in some detail in a forthcoming article by Jody Kollapen and Makubetse Sekhonyane. This forms part of a report by the International Council on Human Rights Policy which investigates the question of human rights in high-crime environments in five countries. 